\title{
How to scale the societal impact of work-integration social enterprises? Evidence from The Netherlands
}

\author{
Leendert de Bell ${ }^{1}$, Linda Drupsteen ${ }^{2}$ \\ ${ }^{1}$ Research Centre for Social Innovation, University of Applied Sciences Utrecht, The \\ Netherlands, ${ }^{2}$ Research Group New Employment Relations, Windesheim University of \\ Applied Sciences, The Netherlands.
}

\begin{abstract}
The number of social enterprises in the Netherlands has increased rapidly. Social enterprises are looking for new, innovative and economically sustainable ways to tackle structural societal challenges that generally fall outside the direct focus and objectives of the public and private sector. Social enterprises are primarily mission-driven, where profit is not a goal in itself but a means of creating societal impact with regard to a specific social problem. Many social enterprises aim to increase their societal impact by growing their organization. However, despite their ambition, scaling up and expanding their impact remains challenging in practice. This research aimed to identify the main constraining factors in scaling up social enterprises and to develop effective methods to tackle these barriers in order to achieve more societal impact. The research was conducted among twenty social enterprises in the Netherlands, all of which aim to stimulate the labor market participation of people who are at a distance from the labor market, generally referred to as work-integration social enterprises. The results show that the majority of the participating social enterprises succeeded in achieving growth in the past two years with regard to specific indicators, but generally not in the way they had originally planned.
\end{abstract}

Keywords: Social Enterprises; Work Integration; Scaling; Societal Impact. 


\section{Introduction}

Social enterprises are looking for new, innovative and economically sustainable ways to tackle structural societal challenges that generally fall outside the direct focus and objectives of the public and private sector (Witkamp et al., 2011). As such, social enterprises are primarily mission-driven, where profit is not a goal in itself but a means of creating societal impact with regard to a specific social problem (Martin \& Osberg, 2007; Nicholls, 2006). The intended impact areas of social enterprises can range from internationally oriented initiatives such as poverty reduction, environmental sustainability, to initiatives to promote the sharing economy or labor market participation.

Over the past decade, the number of social enterprises in the Netherlands has increased rapidly (Bosma et al., 2016). The majority of Dutch social enterprises, around 60\% (Social Enterprise NL, 2015), focus on improving the labor market participation of vulnerable target groups (e.g. people with low labor qualifications, young people disengaged from education, people with mental or physical disabilities, former prisoners, former addicts, people who have difficulties finding a job due to their advanced age, or refugees). The number of people formally registered within this target group in the Netherlands still exceeded 200.000 people in 2017 (UWV, 2017).

Social enterprises contributing to labor market participation are generally referred to as work-integration social enterprises (WISEs). The direct impact of WISEs include offering activation, structure and financial self-sufficiency to the individual. Indirect benefits to the individual may be increasing self-awareness and self-esteem. The broader benefits for society include cost savings on benefits and healthcare. Given the considerable societal challenge, many social enterprises aim to increase their societal impact by growing their organizations. However, previous studies show that scaling up and expanding the societal impact remains challenging in practice, and that many social enterprises fail to have societal impact beyond the local level (Lyon \& Fernandez, 2012; Elkington et al., 2010).

The objective of this research was to identify the main constraining factors in scaling up work-integration social enterprises in the Netherlands and to develop effective methods to tackle these constraints in order to achieve more societal impact and improve the labor market participation of vulnerable target groups. The next section provides a brief explanation of the research design, followed by the most important research results. In the final section, the main conclusions are summarized. 


\section{Methodology}

This research took place from March 2017 to February 2019, and was conducted among twenty work-integration social enterprises in the Netherlands. The participating social enterprises varied in size and in economic sector in which they were active (e.g. IT, catering, facility services, production and assembly) but were primarily selected on the basis of their economically viable business model, with at least $75 \%$ of their revenue generated from the marketplace, and their ambition to increase their societal impact. The research design was divided into five interview rounds and an intervention phase. In each interview round, the researchers conducted in-depth interviews with representatives of all participating social enterprises, usually the founder/owner of the social enterprise. All interviews are structured with the help of a thematic script. All interviews were recorded, then written out and analyzed using qualitative analysis software.

The first two interview rounds formed the basis for the research, and were aimed at gaining insight into the way in which the economic and social value creation of the participating social enterprises is organized. In order to map the economic value creation of the participating social enterprises, a modified "Business Model Canvas" was used. This model, originally designed by Osterwalder and Pigneur (2010), provides insight into the important business aspects in a well-organized manner by means of nine building blocks (value proposition, customer segments, channels, customer relationships, key activities, key resources, key partners, cost structure and revenue streams). With regard to the value proposition and customer segments, an extra distinction is made in the "Social" Business Model Canvas, between the value for paying customers and the value for the target group. Furthermore, an extra category has been added that indicates what will be done with the possible profit (surplus). In the second interview round, the social value creation of the participating social enterprises was mapped using the "Theory of Change" (Clark, 2012). This is a planning model that first defines which long-term objective should be achieved, then which changes should take place, and finally which interventions could produce the desired outcomes.

Interview rounds three and four focused on, respectively, the internal and external barriers that the participating social enterprises encountered in scaling up their activities. The third interview round mapped the power and weaknesses of the internal organization of social enterprises in relation to scaling up. The so-called "SCALERS" model (Bloom, \& Chatterji, 2009), which identifies seven organizational capacities that play an important role in successful upscaling of social enterprises was used: Staffing, Communicating, AllianceBuilding, Lobbying, Earnings-Generation, Replicating, and Stimulating Market Forces (SCALERS in acronym). The fourth interview round aimed at mapping the external environment of the participating social enterprises. To this end, the "Entrepreneurial 
Ecosystem" approach has been used (Stam, 2015). This specific model distinguishes systemic circumstances that are subject to change such as networks, leadership, finance, talent, knowledge, support services, and the more static framework conditions such as institutions, infrastructure, culture, and market. These external factors can both stimulate and hinder the scaling up of social enterprises.

An intervention phase followed, which aimed to develop methods to tackle the observed obstacles to scaling up. These interventions consisted of a number of thematic master classes and an individual consultation with business consultants to address the internal constraints to growth. With regard to external barriers, a number of important stakeholders were consulted, with whom two focus group meetings were organized to increase mutual understanding and arrive at more workable solutions. A final round of interviews was held with representatives of all participating social enterprises, in which they reflected on the development of their social enterprises during the course of the research project (20172019), in order to be able to answer the question to what extent they succeeded in increasing their societal impact.

\section{Main findings}

\subsection{Constraining factors to growth}

After the first four rounds of interviews, five main categories of obstacles to growth were identified: three internal constraints (Human Resource Management, Processes and Systems, Marketing and Branding) and two external constraints (Intake of the target group and Access to finance).

A first internal obstacle for scaling up that was mentioned by the participating WISEs involved good staffing, specifically people who do not belong to the target group, for example coaches or people in staff positions. Guiding and coaching of the target group is generally intensive and therefore expensive, while the financial compensation that is available for coaching the target group is often not sufficient. Since the employment conditions for certain key positions at social enterprises are often less competitive than for comparable positions at regular enterprises, many WISEs experience difficulties in finding experienced and well-qualified people with the required enthusiasm. As a result, the founder/owner often has to do a lot of extra work him or herself.

This also contributes significantly to a second internal obstacle to growth: the absence of a clear structure in processes and systems. Some of the participating social enterprises work mainly on an ad hoc basis, which makes it difficult to replicate the business model. In order to scale up successfully and be able to handle more and larger orders efficiently, 
professionalization and redesign of the organization is often inevitable. This may include automation, outsourcing of activities and entering into new partnerships.

A third internal obstacle to growth is related to communicating the multiple value proposition. With regard to marketing and branding, many companies have doubts if and how they should bring their social message across. Many fear that it may affect their carefully constructed reputation based on quality and service. As a consequence, some WISEs choose not to communicate their social message openly, while, with better marketing and branding of their multiple value, many customers can actually be won here.

One of the most prominent external constraints to growth of the participating WISEs is the intake of the target group. This intake is most commonly organized by local municipalities, which are officially responsible for guiding the target group to the labor market. In practice, however, the matching process of the target group with WISEs is often experienced as extremely difficult. Municipalities do not always have sufficient insight into suitable candidates, which hampers a smooth, low-threshold intake of the target group. As a consequence, many WISEs feel forced to look for candidates through other channels. There are also major differences across the Netherlands in the way in which different municipalities implement the Participation Act (2015). which can be determined by the number of inhabitants of a municipality, the political orientation of the local administration and the composition of the regional labor market. As a result, replicating a proven business model elsewhere is nearly impossible.

An second external constraint for growth, according to the participating WISEs is access to finance. Although most participating social enterprises can count on a stable customer base and a solid revenue stream, the margins are often small. The necessary investments for scaling up consequently almost always require external financing. Although there is a great diversity of financing options, many social entrepreneurs do not know exactly where and when to turn to for financing. Misunderstandings between social enterprises and financial institutions regarding the social and commercial objectives are common. Financial assessment criteria are considered first, while in addition, social enterprises have to meet hard performance requirements with regard to the scalability of the societal impact. The societal impact is generally not that easy to measure, even for financing instruments specifically created for social enterprises, such as the Social Impact Bonds. Consequently, the hybrid objective of these social enterprises often seems to be more of a burden rather than an advantage.

\subsection{Scaling up societal impact}

From the final round of interviews it becomes clear that the vast majority of participating social enterprises have succeeded in achieving growth with respect to one or more indicators over the research span of two years (2017-2019), although the degree of growth 
differs widely between the participating WISEs due to differences in starting positions, economic sectors, and approaches towards the target group. Four indicators of growth that were examined in relation to the starting point include: growth in revenue, growth in the number of customers, growth in the number of employees from the target group and growth in the number of locations (Table 1).

Table 1. Growth indicators of participating WISEs (2017-2019)

\begin{tabular}{|c|c|c|c|c|}
\hline WISEs & Revenue & Customers & Employees & Locations \\
\hline 1 & 0 & 0 & 0 & 0 \\
\hline 2 & + & + & + & + \\
\hline 3 & + & + & + & 0 \\
\hline 4 & + & + & + & 0 \\
\hline 5 & + & + & - & + \\
\hline 6 & + & + & - & 0 \\
\hline 7 & + & 0 & + & 0 \\
\hline 8 & + & + & + & + \\
\hline 9 & + & 0 & + & 0 \\
\hline 10 & + & + & - & 0 \\
\hline 11 & 0 & 0 & 0 & 0 \\
\hline 12 & + & + & + & 0 \\
\hline 13 & 0 & 0 & 0 & 0 \\
\hline 14 & 0 & 0 & 0 & 0 \\
\hline 15 & + & 0 & 0 & - \\
\hline 16 & + & + & + & 0 \\
\hline 17 & + & + & + & 0 \\
\hline 18 & + & 0 & + & + \\
\hline 19 & + & + & + & 0 \\
\hline 20 & 0 & + & + & 0 \\
\hline
\end{tabular}

(+) increase, (0) unchanged, (-) decrease 
As shown in table 1, most participating WISEs experienced growth in revenue. This is an important indicator because it demonstrates that social enterprises are successful in realizing economic value from the market. The majority of the participating WISEs also experienced growth in relation to the second indicator: the number of customers. This is an important condition for achieving the intended social or societal impact, because a larger number of customers generally enables companies to help more people (structurally) at work. With respect to the third indicator, the number of employees from the target group, the majority of the participating WISEs have also effectively succeeded in achieving growth, which directly contributes to their intended growth in societal impact. It is striking that, contrary to the original objectives of many of the participating WISEs, only a small minority have achieved growth by opening up new locations.

With regard to the indicators that remained unchanged or decreased, most WISEs expect this to be temporary, and that investments in professionalizing the organization for example will pay off in growth in impact in the (near) future. It does appear, however, to be particularly difficult for WISEs in the Dutch context to replicate the business model in another location, primarily as a result of the major differences between Dutch municipalities with regard to the way in which the intake of the target group is arranged. Consequently, many social enterprises have instead opted to expand their activities at the existing location(s) rather than set up new ones.

The interviews showed that, on other aspects too, half of the participating social enterprises underwent a major change of direction in the past two years. This is partly inherent to successful entrepreneurship, in which unexpected events are considered opportunities, rather than threats (Sarasvathy, 2001). A number of the participating WISEs have changed their core activities during the course of this research, creating more diverse activities for the target group, or allowing new customers to be served better. Only a small minority of companies have succeeded in scaling up according to a strategic plan that was devised in advance. Often these are companies that have been around for a longer time and have their organization and governance structures in place. However, proportionally the size of their growth is often smaller than that of those companies that have undergone a change of direction.

Only four out of twenty companies failed to scale up at all. One of the main reasons for this seems to be a limited capacity to cope with financial setbacks, for example as a result of long-term absenteeism on key functions or other unforeseen costs. Often, these companies also struggle to reconcile social and economic value creation. Due to their limited size and small profit margins, these social enterprises have difficulties in overcoming unexpected financial blows. Moreover, prolonged crisis management leaves too little time for activities that could reverse this trend, such as acquisition, or more attention to strategy. 


\section{Conclusions}

Scaling up is a complex process for any company because it involves changes in organization, working methods and sometimes objectives. Work-integration social enterprises differ in several important areas, not only with respect to for-profit enterprises but also with regard to social enterprises that focus on other societal impact areas. For instance, by working with specific target groups, WISEs have to have their human resource management in place from the very start, whereas other starting companies generally have to deal with these issues in a later stage and in a more organic fashion. Additionally, WISEs often have to deal with major differences in local contexts, for example with regard to the way in which the intake of the target group is organized. This makes it far from self-evident that their business model can be replicated elsewhere.

Nevertheless, this research shows that it is indeed possible for WISEs to scale up successfully and to increase their societal impact. Whether or not a social enterprise is able to scale up depends strongly on the way in which they deal with several barriers at the individual, organizational and external ecosystem level. An important precondition for scaling up is that, first and foremost, sufficient economic value is created. The pursuit of multiple value creation always creates tensions, but without a financially sound company it is not possible to create the intended societal impact. The most successful social enterprises in this project succeeded in acquiring substantial orders and structurally commiting customers in order to achieve the desired societal impact.

A second precondition is a professional organization. Professionalization of the internal organization provides the necessary basis from which the social enterprise can grow further. The most successful social enterprises in this project demonstrated their ability to overcome the various obstacles they encountered at the start of the project. We observed that an organizational structure has been or is being built, in which the most important tasks are divided between several people, and where the day to day processes have been structured. These companies are no longer dependent on one person -usually the founder- but have a team of qualified people who keep the organization running and allow for the further expansion of the social enterprise.

This research shows that there are different routes to scale up and to reach more people with a distance to the labor market, but that this route often cannot be precisely planned in advance. Half of the participating social enterprises have succeeded in realizing growth only after adjusting one or more aspects of their business model. Changes in direction may be necessary when certain obstacles stand in the way of further growth, such as too little intake from the target group or the loss of an important customer. However, changes in direction can also be the result of unexpected events that offer new opportunities, such as new partnerships with other companies or municipalities. For most social entrepreneurs it is 
not always that easy, however, to make adjustments to their business model along the way because their intended social long-term objective -participation of people at a distance from the labor market- can also (emotionally) stand in the way of drastic changes in direction.

\section{References}

Bloom, P. \& Chatterji, A. (2009) Scaling Social Entrepreneurial Impact. California Management Review, 51(3), 114-133.

Bosma, N., Schott, T., Terjesen, S., \& Kew, P. (2016) Global Entrepreneurship Monitor 2015: Special Topic Report Social Entrepreneurship. Global Entrepreneurship Research Association.

Clark, H. (2012) Theory of Change: Value added and complementarity with Results-based Frameworks and Scorecards. New York: ActKnowledge.

Elkington, J., Hartigan, P., \& Litovsky, A. (2010) 'From Enterprise to Ecosystem. Rebooting the Scale Debate' in Bloom, P. \& Skloot, E. (eds.) Scaling Social Impact: New Thinking. New York: MacMillan, 83-102.

Lyon, F. \&, Fernandez, H. (2012) Scaling Up Social Enterprise: Strategies Taken from Early Years Providers. Working Paper 79, Third Sector Research Centre.

Martin, R. \& Osberg, S. (2007) Social Entrepreneurship: The Case for Definition. Stanford Social Innovation Review.

Nicholls, A. (ed.) (2006) Social Entrepreneurship. New Models of Sustainable Social Change. Oxford: Oxford University Press.

Osterwalder, O., \& Pigneur, Y. (2010) Business Model Generation. A Handbook for Visionaries, Game Changers, and Challengers. Hoboken: John Wiley

Sarasvathy, S. (2001), Causation and Effectuation: Toward a Theoretical Shift from Economic Inevitability to Entrepreneurial Contingency. Academy of Management Review, 26(2), 243-263.

Social Enterprise NL (2015) De Social Enterprise Monitor 2015. Amsterdam: Social Enterprise NL.

Stam, E. (2015) 'Entrepreneurial Ecosystems and Regional Policy: A Sympathetic Critique'. European Planning Studies, 23(9), 1759-1769.

UWV (2017) Monitor Arbeidsparticipatie 2017. Aan het werk zijn, komen en blijven van mensen met een arbeidsbeperking. Amsterdam: Uitvoeringsinstituut Werknemersverzekeringen

Witkamp, M., Royakkers, L., \& Raven, R. (2011) From Cowboys to Diplomats: Challenges for Social Entrepreneurship in The Netherlands. Voluntas, 22, 283-310. 